\title{
An appraisal of the properties of bottom waste obtained from bio-mass congestion to estimate the ways of its environmental use
}

\author{
Małgorzata Śliwka*, Alicja Uliasz-Bocheńczyk, Małgorzata Pawul \\ AGH - University of Science and Technology, Faculty of Mining and Geoengineering, Department of Environmental \\ Engineering and Mineral Processing, al. Adama Mickiewicza 30, 30-059, Krakow, Poland \\ "Corresponding author: e-mail: sliwka@agh.edu.pl
}

\begin{abstract}
The bottom waste obtained from bio-mass burning shows a huge variability of chemical and physical properties, depending on the kind of bio-mass, the type of a cauldron and burning parameters. The huge variability of the bottom ashes from the incineration plant and co-combustion of bio-mass makes it difficult to find any way to its management. In reality, only the bottom ashes from coal combustion and the small amount from lignite combustion are used, mainly in the building industry and in mining industry. The article presents the initial research, concerning the estimation of the properties of the bottom ashes obtained from bio-mass congestion in the fluidized- bed boiler to use them safely for the environment. To determine the influence of the tested waste on plants, a number of pot experiments have been conducted. The plants which have been used are recommended for phytotoxicity estimation, and are also used for biological reclamation.
\end{abstract}

Keywords: bottom waste, bottom ashes, bio-mass combustion, bio-mass, fluidized-bed boiler, bio-tests, phytotests, energy wastes, furnace waste.

\section{INTRODUCTION}

The production of electrical energy in Poland is connected with waste production. The characteristics of these wastes depend on the type of the fuel and the type of the boiler. These wastes are mainly the side products of coal burning in conventional boilers. However, during last years, the significant group of the energy wastes is a side product of the combustion in fluidized-bed boilers. The increase in popularity of the fluidized-bed boilers comes from their emission characteristic.

The commercial power industry has changed its fuel profile, as well. Alongside with the coal and lignite, the bio-mass is also combusted. The combustion of the latter one is connected with the requirement of obtaining energy from the renewable sources. This requirement is realized in a co-combustion processes with coal, and also in bio-mass alone combustion in the separate, especially designed boilers ${ }^{1}$.

The process of combustion in fluidized-bed boilers causes waste production. These wastes are divided into following groups ${ }^{2}$ :

- fly ashes,

- bottom wastes (called also bottom ashes, compound ashes or compound wastes).

According to the regulation of the Ministry of Environmental Protection of 9 December 2014 on the catalogue of waste (Journal of Laws 2014, pos. 1923) , $^{3}$ the wastes mention above, are classified in the group 10 - thermal processes waste; subgroup 1001 - wastes from the energy plants and other plants dealing with the combusting fuels to obtain energy (excluding group 19). The regulation determines two types of wastes from fluidized-bed boilers:

- the mixture of fly ashes and firm wastes of calcium methods of waste gases desulphurization (dry, semi-dry methods of fumes desulphurization and combustion in fluidized lode) (10 01 82);

- sand from the fluidized lode (excluding 100182 ) (10 01 24).
Mixtures of fly ashes and firm waste of calcium methods of waste gases desulphurization (dry, semi-dry methods of fumes desulphurization and combustion in fluidized lode) (10 0182 ) of coal combustion are used mainly in road construction to produce building materials (cement among them) and in mining industry ${ }^{4,5}$. Wastes 1001 24 from lignite combustion are used in the minimum range $e^{1,5,6}$.

Within the waste group marked as 100182 there are also side products of combustion in the amount of 3.8 thousand tones in the plants where the bio-mass is combusted, but they are not managed yet. The bottom wastes from combustion and co-combustion of the bio-mass are characterized by high variability of physical and chemical properties, depending closely on the type of combusting bio-mass, what determines the possibilities of their management and limits the usage of bottom waste in reality. The research conducted on the impact of the bottom furnace waste from the bio-mass confirm the beneficial influence of such waste on the plant growth and the possibility of the environmental use in order to improve the properties of soil and as a source of nutrients for the plants ${ }^{7,8}$. The wastes are also recommended to salvage within R109.

\section{MATERIAL AND METHODS}

The aim of the research was to analyze the physical, chemical and toxicological properties of the bottom waste from bio-mass combustion to find its environmental use. The tested samples were taken from bottom waste from the bio-mass combustion in the fluidized-bed boiler.

These wastes contain big amount of $\mathrm{SiO}_{2}$ and $\mathrm{CaO}$ (Table 1) and show a strong alkaline reaction $(\mathrm{pH}>12$ for both tested samples).

The method of dry sieving has been used to analyze the grain composition of the testes wastes. The chemical analysis of ashes has been conducted with the use of X-ray spectrometer MobiLab X5000 (fraction $\phi<2 \mathrm{~mm}$ ), 
Table 1. Chemical composition of waste 100124 used for research

\begin{tabular}{|l|c|c|}
\hline Component & Waste B [\%] & Waste T [\%] \\
\hline $\mathrm{SiO}_{2}$ & 42.0 & 90.0 \\
\hline $\mathrm{Fe}_{2} \mathrm{O}_{3}$ & 3.5 & 1.0 \\
\hline $\mathrm{Al}_{2} \mathrm{O}_{3}$ & 14.5 & 2.5 \\
\hline $\mathrm{CaO}$ & 20.1 & 3.0 \\
\hline $\mathrm{MgO}$ & 1.7 & 0.7 \\
\hline $\mathrm{SO}_{3}$ & 12.0 & 0.3 \\
\hline Loss on ignition & 1.0 & 0.4 \\
\hline
\end{tabular}

$\mathrm{pH}$ of the aqueous extract of the each of the growing media used for the pot experiment has been measured.

To determine the influence of the tested materials on germination, growth and the general condition of the plants (Lepidium sativum, Sinapis Alba, Frestuca rubra), the initial pot experiments have been conducted. The chosen species of plants Lepidium sativum, Sinapis Alba are recommended as testing samples used in phytotests to estimate the toxicity of different materials ${ }^{\mathbf{1 0}, 11,12}$ and Frestuca rubra is used to biological reclamation in the case of alkaline subsoil ${ }^{13,14,15}$.

The test plants have been grown on the universal soil mixed with the experimental material (B- Waste B, T-Waste T). In each of the pot ten seeds of test plants have been planted. The seeds were of the same size and in the same condition. The experimental groups have been varied according to the content of the testes wastes in the soil $(10,20,30$, and $40 \%$ of the waste in the sample). In order to compare the influence of the waste on the test plants the reference group of pure soil (ktr - control group) has been prepared. All the observations have been conducted in four repetitions. All the plants have been grown in laboratory conditions to assure the same growth environment for the entire test groups (humidity, light access).The observation of test plant germination and growth were conducted for seven days in the case of Lepidium sativum, Sinapis alba and for fourteen days in the case of Frestuca rubra. After three days of cultivations, the germination of Lepidium sativum and Sinapis alba was estimated, the same was done in the case of Frestuca rubra, but after seven days. After seven and fourteen days the growth of the overground parts ( $\mathrm{Z}$ - green shoots), and roots ( $\mathrm{K}$ - roots) of the test plants were measured to determine the influence of the waste on the plant development. At the same time the morphological changes were observed. A nonparametric test by Kolmogorow-Smirnow with the use of Statistica (version 10) program was used to obtain the statistical estimation.

\section{RESULTS AND DISCUSSION}

The physical and chemical analysis of the tested material revealed significant differences among the properties of examined materials (Waste B, Waste T). The ashes showed different grain compound (Figs.1, 2).

The majority of the waste $\mathrm{B}$ consisted of the grain fractions $0.063-0.2 \mathrm{~mm}(>88 \%)$, in the waste $\mathrm{T}$ the majority was of fraction $0.2-0.63 \mathrm{~mm}(>88.5 \%)$, what significantly influenced on the physical properties of the experimental soils. The soils containing the addition of waste B (30\%, $40 \%$ ) became firm and this prevented germination and the growth of the plant in this soil (Lepidium sativum,

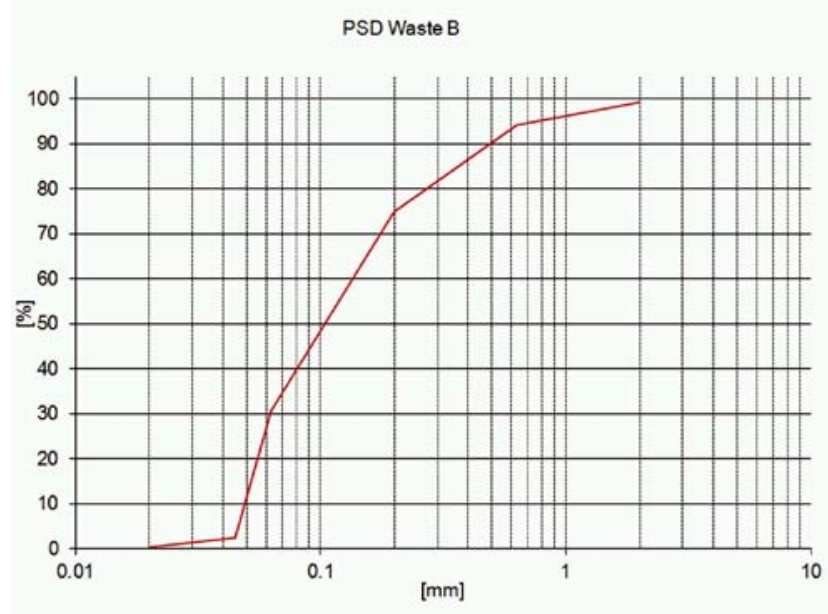

Figure 1. The curve of particle size distribution for the sample of the waste B (the dry sieve method)

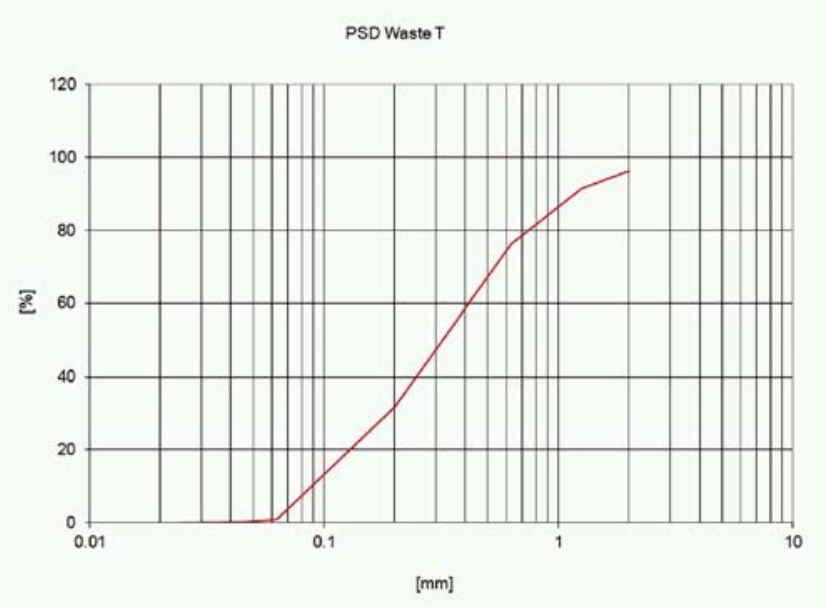

Figure 2. The curve of particle size distribution for the sample of the waste $\mathrm{T}$ (the dry sieve method)

Sinapis alba). The addition of waste $\mathrm{T}$, because of the content of the grain fraction of a bigger diameter, may beneficially influence the looseness of the soil and improve its air and water properties. The addition of the strong alkaline ashes caused the increase of the $\mathrm{pH}$ in the soil from 7.7 to 9.2 (proportionally according to the increase of the amount of waste additive 10-40\%), whereas the addition of the waste $B$ influenced on the increase of the $\mathrm{pH}$ from 9.3 to 11.7 (according to the increase of the amount of the waste 10-40\%)

The XRF analysis revealed the content of macro and micro nutrient components in both tested wastes. This fact contributes to fertilize properties of the ashes e.g. K, $\mathrm{P}, \mathrm{Ca}, \mathrm{S}, \mathrm{Zn}, \mathrm{Fe}$ and $\mathrm{Mn}$. The presence of the phytotoxic heavy metals like as $\mathrm{Pb}$ was revealed in the ashes. In the waste $\mathrm{B}$ the amount of the $\mathrm{Pb}$ was established on the level of $100 \mathrm{ppm}$, but in the waste $\mathrm{T}$ the content of $\mathrm{Pb}$ was in the level of $20 \mathrm{ppm}$. The average natural content of $\mathrm{Pb}$ in Polish soil achieves the level of $18 \mathrm{ppm}$, and should not exceed $20 \mathrm{ppm}$. The most frequent border limit for the contaminated soils reaches 100 ppm (depending on the specific properties of the soil may reach $500 \mathrm{ppm}$ ). Unfortunately, these values are exceeded in most of the contaminated soils e.g. in Górny Śląsk (Higher Silesia), 
locally the total content of lead in the upper layers of the soil reaches the amount of $6000-8000 \mathrm{ppm}^{16}$.

The analysis of the vase tests' results revealed significant differences in germination and growth of the plants growing on the experimental soils. The statistical analysis of the obtained results showed significant differences between the experimental groups and the control group for most of the experimental group, especially those ones with bigger content of tested waste in the soil (Figs. 3, 4, 5).

\section{Lepidium sativum}

Median; Percentile factors: 25\%-75\%; Whisker: Min-Max

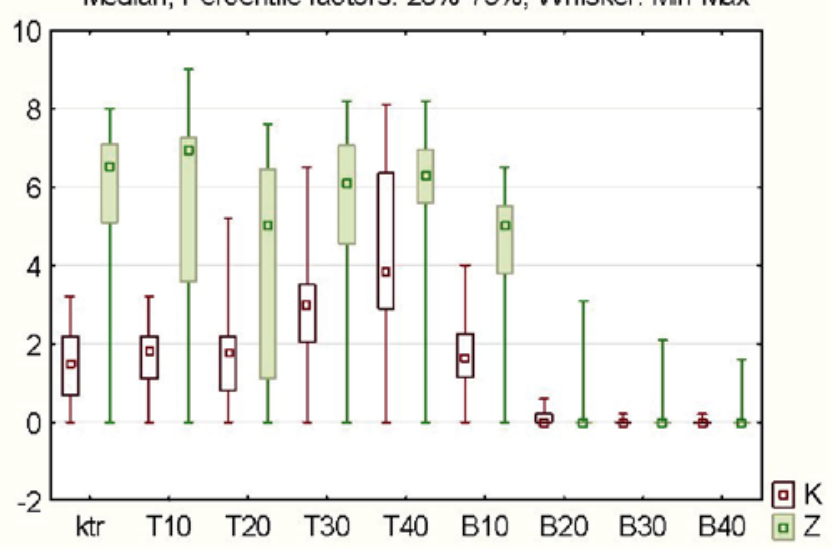

Figure 3. The statistical distribution of results for the experimental groups of Lepidium sativum

Sinapis alba

Median; Percentile factors: 25\%-75\%; Whisker. Min-Max

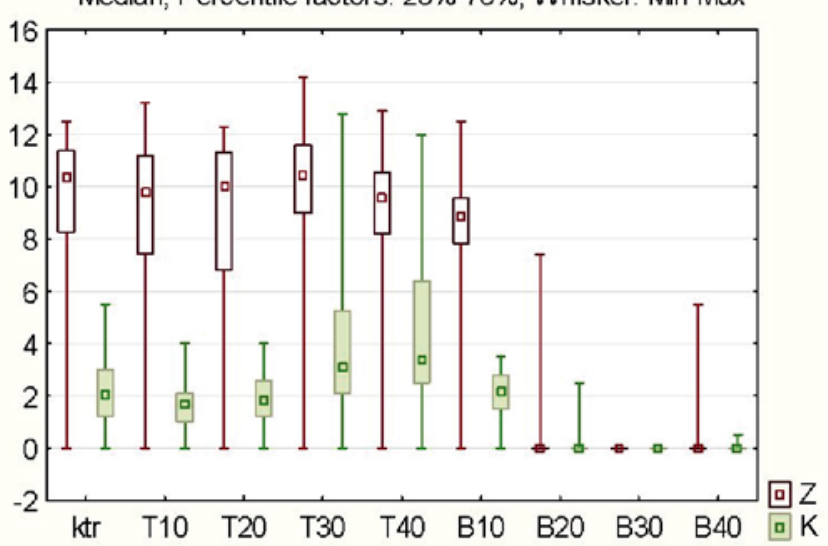

Figure 4. The statistical distribution of results for the experimental groups of Sinapis alba

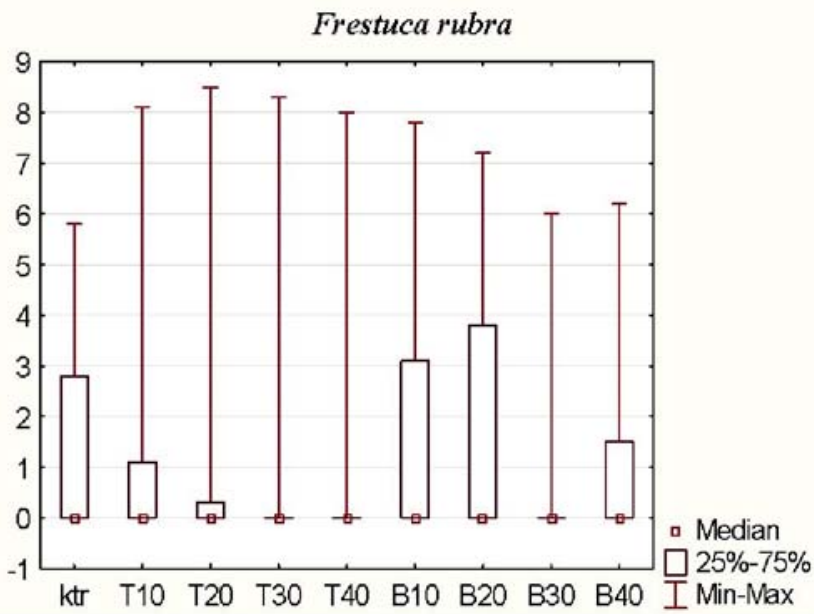

Figure 5. The statistical distribution of results for the experimental groups of Frestuca rubra
The inhibition of the germination has been observed among plants Lepidium sativum and Sinapis alba in the experimental groups with the admixture of Waste B with the content of $20,30,40 \%$ of the Waste B in the universal soil (Figs. 6, 7).

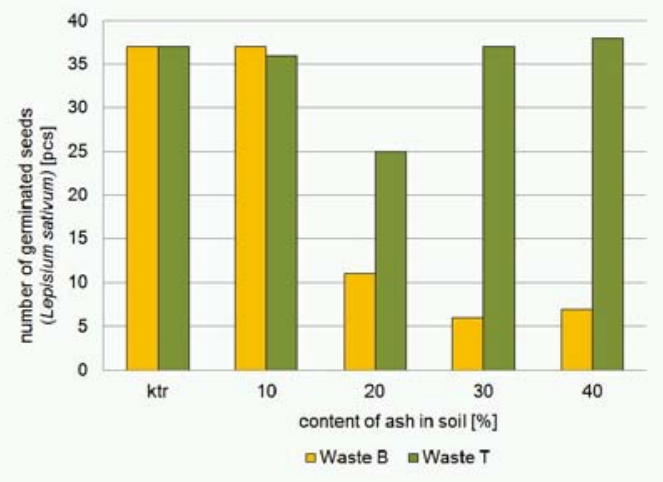

Figure 6. The comparison of germination of Lepidium sativum on the third day of the experiment

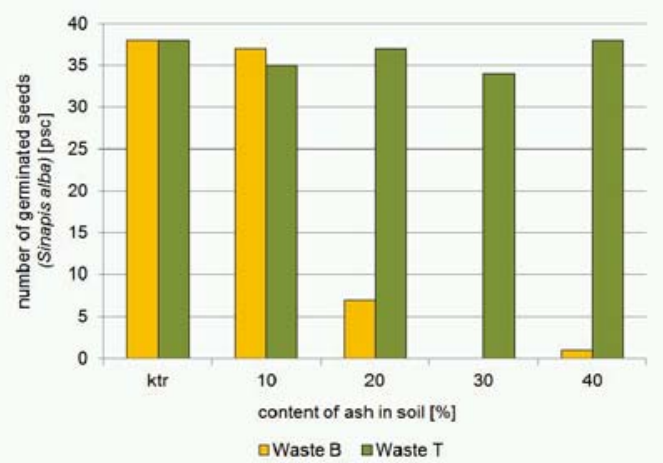

Figure 7. The comparison of germination of Sinapis alba on the third day of the experiment

The inhibition of germination of Lepidium sativum has not been observed in the group which contained $10 \%$ of the Waste B in comparison with the control group (Fig. 6). The plants grown on the soil with ashes were in much worse condition (weaker growth, yellow discoloration on leaves) in comparison with the control plants. Sinapis alba, which was seeded into universal soil with the $10 \%$ of admixture, showed a good tolerance to the Waste B in the amount of $10 \%$ (Fig. 7). Frestuca rubra showed the best tolerance to the Waste B in amounts $10 \%$ and $20 \%$. The significant inhibition in germination has been observed in the coil with the ash content of $30 \%$ and $40 \%$ in the soil (Fig. 8).

The content of Waste B in the soil where the tested plants were grown influenced significantly on their growth and development (all species) in all experimental groups (Figs. 9, 10, 13).

The plant development (the growth of shoots and roots) depended on the bottom ash content which influences the solidification of the substrate, germination and growth hindering. The plant development has been also affected by the alkaline reaction of the sediment (depending on the specific demands of species), and nutrients availability (depending on $\mathrm{pH}$ ). 


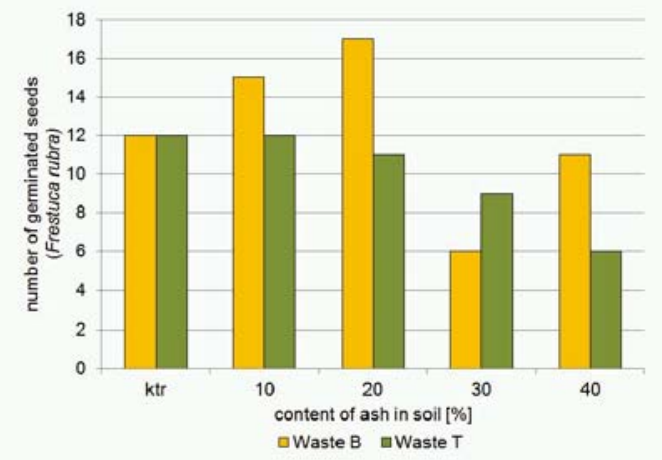

Figure 8. The comparison of germination of Frestuca rubra on the seventh day of the experimen

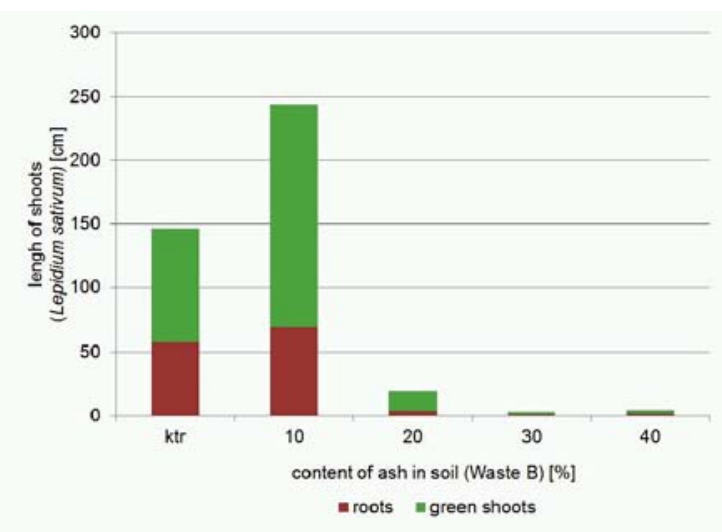

Figure 9. The comparison of growth of green shoots and roots of Lepidum sativum in the seventh day of the experiment

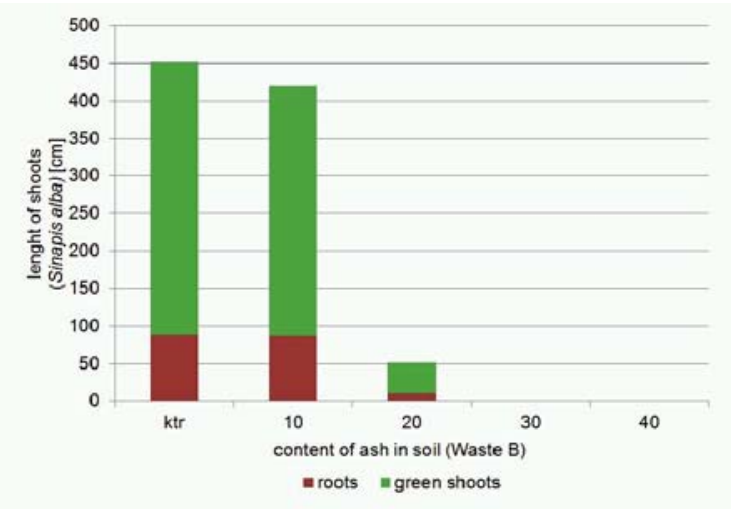

Figure 10. The comparison of growth of green shoots and roots of Sinapis alba in the seventh day of the experiment

The addition of the Waste $\mathrm{T}$ to the soil has not a significant influence in the inhibition of seeds germination among the experimental groups (Figs. 6, 7, 8). The experimental groups of Sinapis alba with the bigger amount of bottom ash in the soil $(30 \%, 40 \%)$, showed a better growth of green shoots and a better development of roots (Fig. 11).

The garden cress (Lepidum sativum)grown in the soil with the addition of the Waste T showed more developed rhizosphere in the groups of higher content of waste $(30 \%, 40 \%)$ in the comparison with the control group and the groups with the smaller content of waste. The growth of the stems were slightly smaller in the groups with the bigger content of the Waste T (Fig. 12).
The growth of the stems of red fescue (Festuca rubra) in groups with the bigger content of the bottom ash (Waste $\mathrm{T}$ ) in the soil was lower in comparison with the experimental groups with the lower content of waste in the soil, and the plant of the control group (Fig. 13).

The different reactions of the tested plants to the additive of the bottom furnace waste (Waste B, Waste T) to the soil derive from the specific growing properties of each test plant. The reaction was also determined by the type of waste added to the soil. The Waste B caused the solidification of the substrate what prevented the germinations of the plant, especially in the case of Lepidium sativum and Sinapis alba. Frestuca rubra showed better ability of germination and development in the environment of the biggest content of waste.

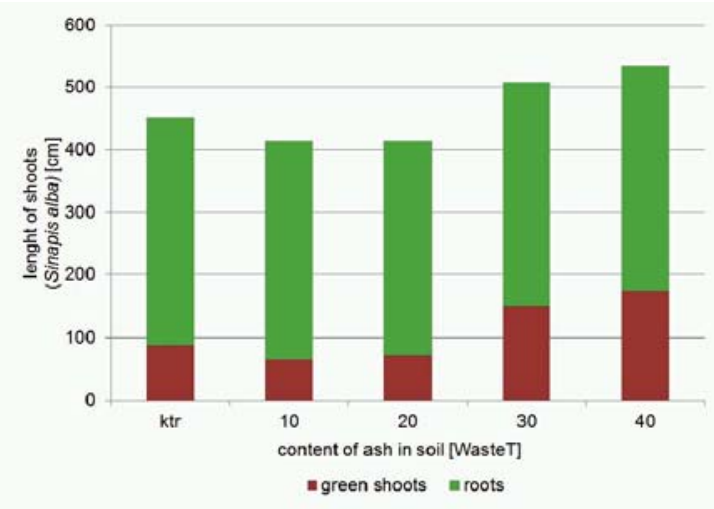

Figure 11. The comparison of growth of green shoots and roots of Sinapis alba in the seventh day of the experiment

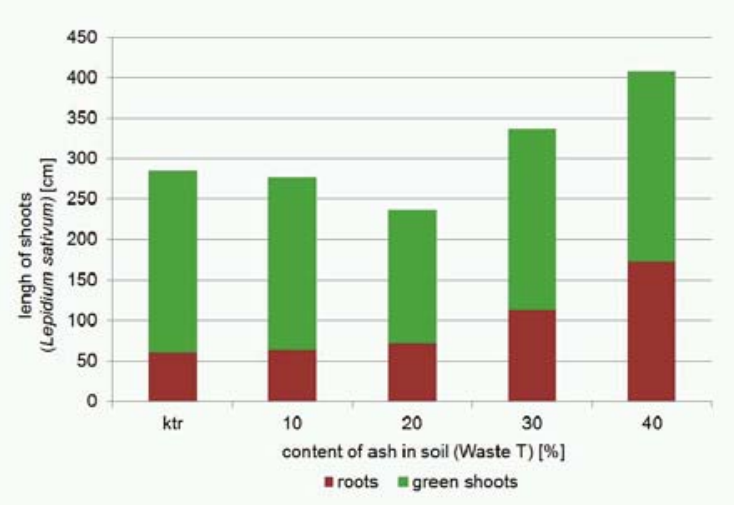

Figure 12. The comparison of growth of green shoots and roots of Lepidum sativum in the seventh day of the experiment

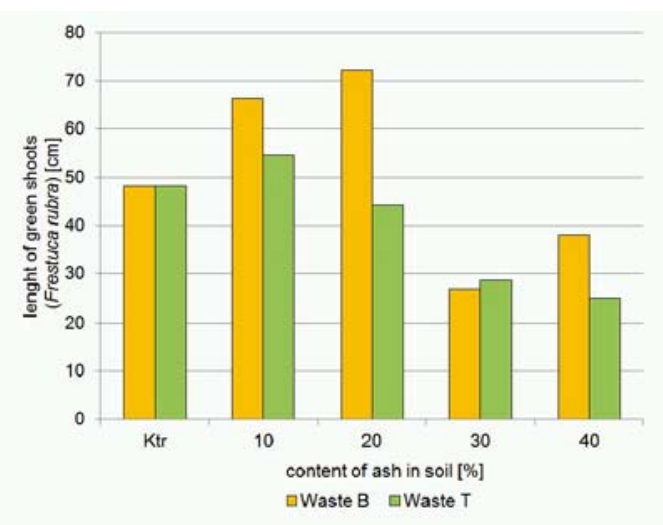

Figure 13. The comparison of growth of green shoots of Festuca rubra in the fourteenth day of the experiment 
The addition of the Waste $\mathrm{T}$ may be beneficial not only for the soil structure (grain compound), but also for the plant growth and development (a better developed rhizosphere with the experimental plants).

\section{CONCLUSIONS}

The initial results of the conducted vegetation experiments and physical-chemical properties of the wastes reveal a possibility for the environmental management of the tested bottom waste from the bio-mass combustion. However, this possibility depends closely on the waste properties. The experiments proved a varied influence of the each type of waste on the plant growth and development. This was caused by the amount of the waste in the soil and different physical and chemical properties of waste, although both tested types of waste are marked by the code 100182 .

The different reactions of the test plants to the additive of the tested waste to the soil were depended on the waste properties as well as the features of plant species and their adaptive properties:

1. The addition of the Waste B in an amount of $20 \%$, $30 \%$ and $40 \%$ caused inhibition of germination of Lepidium sativum and Sinapis alba. (Both plants species are sensitive to unfavorable environmental conditions and are recommended for phytotoxicity tests). The cause of this reaction might be a high $\mathrm{pH}$ of the substrate and its ability to the solidification, which might inhibit the germination. The addition of the Waste B in an amount of $10 \%$ and $20 \%$ was tolerated by Festuca rubra. This species is used to biological reclamation and it tolerates alkaline soil.

2. The addition of the Waste B to the soil had a significant impact on the inhibition of the growth of overground parts and roots of all species of test plants.

3. The addition of the Waste $\mathrm{T}$ to the soil had not a significant impact on the inhibition of test plants germination.

4. Lepidium sativum and Sinapis alba planted in the soil with the higher addition of the Waste $\mathrm{T}(30 \%$ and $40 \%$ ) showed better growth of roots and similar growth of overground parts in the comparison with the control group, while the growth of Festuca rubra was lower (for $30 \%$ and $40 \%$ content of the Waste $\mathrm{T}$ in the substrate).

5. Physico-chemical properties of the waste with a high content of fine-grained fraction $(<0.2 \mathrm{~mm})$ may be modified by the addition of sand or coarse-grained ash. It may have a beneficial impact on the structure of the substrate and reduce its tendency to solidification.

The initial observations prove the opinion that the bottom ashes can modify the physical properties of soil, and can be the source of nutrients for plants. Due to the changeable chemical compound of waste depending on the type of combusted bio-mass, and the combusting conditions it is really important to analyze the chemical compound of the waste because of the possible occurrence of heavy metals. Because of the strong alkaline character of the waste, it can be used on acidic soils to deacidification or to limitation of the toxic compound access (e.g. decrease in bio-accessibility of heavy metals) provided that the content of heavy metals in the bottom ashes will not worsen the quality of the soil.

\section{ACKNOWLEDGMENT}

The task have been made within the statutory research of the Environmental Engineering and Mineral Processing (No 11.11.100.482), the Department of Mining and Geoengineering, AGH University of Science and Technology in Cracow.

\section{LITERATURE CITED}

1. Energy Market Agency. (2013). Emitor. Emission of envirmnental pollution from heating plants and power plants. Warsaw (in Polish).

2. Galos, K., Gawlicki, M., Hycnar, E., Lewicka, E., Nieć, M., Ratajczak, T. \& Szlugaj, J., Wyszomirski P. (2009). Raw materials from mineral waste. Ed. IGSMIE PAN, Krakow (in Polish).

3. Regulation of the Minister of Environmental of 9 December 2014 on Catalog of Wastes (2014). (Journal of Laws 2014, pos. 1923 (in Polish).

4. Energy Market Agency. (2014). Emitor. Emission of envirmnental pollution from heating plants and power plants. Warsaw (in Polish).

5. Uliasz-Bocheńczyk, A., Mazurkiewicz, M., Mokrzycki, E. (2015). Fly ash from energy production - a waste, by product and raw material. Gospod. Surow. Miner. 31, 139-150. DOI: 10.1515/gospo-2015-0042

6. Energy Market Agency. (2015). Emitor. Emission of envirmnental pollution from heating plants and power plants. Warsaw (in Polish).

7. Antonkiewicz, J. (2009). The use of bottom ash to bind of heavy metals in soil. Ochr. Śr. Zasobów Nat. 41, 398-405 (in Polish).

8. Poluszyńska, J. (2013). Possibility of using ashes from biomass combustion in the management of sewage sludge. Pr. Inst. Cer. Mater. Bud. 13, 49-59. Opole (in Polish).

9. Portal of the National Forum of Biomass Combustion. Retrieved February 29, 2016, from www.spalaniebiomasy.pl

10. Traczewska, T.M. (2011). Biological methods to assess of environmental pollution. Ed. Wroclaw University of Technology (in Polish).

11. Śliwka, M., Baran, A. \& Wieczorek, J. (2013). Evaluation of toxic metal bioaccumulation in a reservoir of flotation tailings. Pol. J. Environ. Stud. 22(3) 909-914.

12. Baran, A. Śliwka, M. \& Lis, M. (2013). Selected properties of flotation tailings wastes deposited in the Gilów and Żelazny Most waste reservoirs regarding their potential environmental management. Arch. Mining Sci. 58(3) 969-978. DOI: http://dx.doi.org/10.2478/ amsc-2013-0068

13. Góral, S. (2001). Plants in protection end reclamation of soils. Inżynieria Ekologiczna 3, 161-178 (in Polish)

14. Góral, S. \& Rola S. (2001). Grasses on the ashes from power plants fertilized with sewage sludge. Inż. Ekol. 3, 146-150 (in Polish).

15. Dyguś, K.H., Siuta, J., Wasiak, G. \& Madej, M. (2012). Plants of municipal and industrial waste landfills. Monography. Publishing House of the University of Ecology and Management in Warsaw (in Polish).

16. Kabata-Pendias, A. (2011). Trace Elements in Soils and Plants (4th ed.). CRC Press Taylor \& Francis Group, LLC. 